\title{
EVALUATION OF MASTICATORY MUSCLE ACTIVITY IN COMPLETE DENTURE WEARERS BEFORE AND AFTER PROSTHETIC TREATMENT
}

\author{
Joanna Kuć, Teresa Sierpińska, Maria Gołębiewska \\ Department of Prosthodontics, Medical University of Bialystok, Poland
}

\begin{abstract}
INTRODUCTION: Muscle activity associated with mandible mobility depends on age. In the period of puberty and development of the masticatory system, a general increase in activity is observed, followed by relative stability until about 40-50 years of age. In subsequent years, the value of bioelectrical potentials decreases.

Овјестіves: The aim of the study was to evaluate activity of the chewing muscles in complete denture wearers before and after prosthetic treatment.

MATERIAL AND METhoDS: The study group consisted of 50 edentulous people including 35 women and 15 men (age 44-86 years, mean 69.18 \pm 10.00 ). All the patients received a new set of complete dentures. The activity of the following pairs of muscles were measured: anterior part of the temporal, masseter, digastric, and sternocleidomastoid. All registrations were performed three times: with the presence of currently used old dentures, in the first day of using new dentures, and three months after adaptation. Activity of the muscles was noted in the maximum intercuspation and with opened mouth.

RESULTS: The results of this study revealed statistically significant differences in activity of the temporal, masseter, and digastric muscles before and in the first day of using new dentures. After three months of adaptation statistical differences were observed only in the case of masseter muscles, right temporal, and left digastric. In the first day of using new complete dentures a decreasing tendency of muscular activity was noted. After three months of adaptation the muscular activity increased.

ConcLusions: Fabrication of new complete dentures associated with reconstruction of vertical occlusal dimension, changes in the central position of the mandible, and modification of the occlusion of the artificial teeth leads to a temporary reduction of activity in the chewing muscles and then, after a period of adaptation and incorporation, to growth.
\end{abstract}

KEY WORDS: complete denture, edentulism, electromyography, muscular activity.

J Stoma 2019; 72, 2: 43-51

DOI: https://

\section{INTRODUCTION}

Muscle activity associated with mandible mobility depends on age. In the period of puberty and development of the masticatory system, a general increase in ac- tivity is observed, followed by relative stability to about $40-50$ years of age. In subsequent years, the value of bioelectrical potentials decreases [3, 5, 6, 22, 25, 35]. Alajbeg et al. [1], when comparing groups of patients with preserved natural dentition and different age brackets, stated higher muscular activity among young people

JOURNAL OF STOMATOLOGY CZASOPISMO STOMATOLOGICZNE

AdDRess FOR CORRESPONDENCE: Joanna Kuć, Department of Prosthodontics, Medical University of Bialystok, 24A M. Skłodowskiej-Curie St., 15-276 Bialystok, Poland, e-mail: kucjoanna@poczta.onet.pl

ReCeIved: 07.03.2019 • ACCEPTED: 2.05.2019 • PUBlished: 19.07.2019 
$(26.7 \pm 2.8)$ both in central occlusion and in maximum opening of the mouth. On the other hand, in eccentric, lateral movements the predominance of potential values in patients in adulthood $(60.9 \pm 7.8)$ was noted. This is probably the result of the forced intensification of stimuli leading to the same chewing efficiency as in the younger generation, although in older people it requires greater involvement of the muscles [1]. The cause is probably the modification of the occlusal condition of the teeth. Age-related - and induced by pathological tooth wear inversion of the canine guidance towards the group function, as well as translocations in the scope of the teeth determining the profile of occlusion, intensify the muscular activity [1]. It should be emphasised that the tooth wear process is a physiological phenomenon progressing gradually from the age of 35 years with an average reduction of hard tissues in the range of $65 \mu \mathrm{m} /$ year [7].

Considering that fabrication of new complete dentures is associated with reconstruction of the vertical occlusal dimension, changes of the central position of the mandible, and modification of the occlusion of the artificial teeth, it was suggested that after prosthetic treatment, activity of the chewing muscles could also be changed. It was hypothesised that activity of the muscles could be differentiated in terms of gender.

\section{OBJECTIVES}

The aim of the study was to evaluate the activity of the chewing muscles in complete denture wearers before and after the prosthetic treatment.

\section{MATERIAL AND METHODS}

\section{THE SUBJECTS AND SAMPLE SIZE}

The study group consisted of 50 edentulous people, including 35 women and 15 men (age $44-86$ years, mean $69.18 \pm 10.00)$. All the patients were referred to change their currently used complete dentures. Mean denture wearing time was $10.80 \pm 9.15$ years, and the average time of toothlessness was $17.0 \pm 9.0$ years. Exclusion criteria were any complaints within the masticatory system and some disorders that have a potential impact on the masticatory muscle activity (bruxism, multiple sclerosis, neurological diseases). Patients with asthma, diabetes, calcium and phosphate dysregulation, corticosteroid therapy, alcohol addiction, hormone replacement therapy, and osteoporosis were also excluded from participation in the study.

\section{CLINICAL PROCEDURE}

All the patients received a new set of complete dentures fabricated with respect to current, general stan- dards of treatment. The mean value of the vertical occlusal dimension (distance between soft tissue subnasale and soft tissue menton) in formerly used prostheses was $67.21 \mathrm{~mm}$, and after the rehabilitation on the first day of using the new dentures it was $71.65 \mathrm{~mm}$. Electromyography registration was performed by using a BioEMG device (BioRESEARCH, Inc., Milwaukee, Wisconsin, USA). During the clinical procedures the patient was in a sitting position in the dental chair. Activity of the muscles was registered by using self-adhesive, bipolar electrodes covered by silver chloride $(\mathrm{Ag} / \mathrm{AgCl})$. Each pair of electrodes contained a constant separation between the poles $(19 \mathrm{~mm})$. Facial skin was rinsed with $2 \%$ salicylic alcohol to decrease impedance. All electrodes were positioned over muscle bulk, palpated in the contraction, parallel to muscular fibres. The zero electrode was positioned over the right supraclavicular fossa. The activity of the following pairs of muscles was measured: anterior part of the temporal, masseter, digastric (venter anterior), and sternocleidomastoid. All registrations were performed three times: with the presence of currently (initially) used dentures, on the first day of using new dentures, and three months after adaptation. Activity of the muscles was noted in the maximum intercuspation and with an opened mouth. Patients were instructed to clench their teeth together, stay in this position for a while (2s), and then open the mouth wide and repeat these steps two times more. All measurements were performed three times with a one-minute interval between registrations.

\section{STATISTICAL ANALYSIS}

Statistical analysis was conducted using Statistica 12 Software (StatSoft Power Solutions, Inc.). All measurements were evaluated three times and averaged. To evaluate distribution of quantitative variable measures of central tendency and variation were used (respectively, arithmetic mean, median, and standard deviation). Student's $t$-test and Wilcoxon test were used to compare activity of the muscles noted at stages I, II, and III of the observation (in the presence of initially used dentures, on the first day of using new dentures, and three months after adaptation). Mann-Whitney $U$ test was used to compare the activity of the chewing muscles at each stage of the study (I-III) in groups separated with respect to gender. Differences were considered to be statistically significant at $p<0.05$.

\section{ETHICAL APPROVAL}

The clinical protocol was approved by the Institutional Bioethics Committee; the number of the approval was R-I-002/88/2008, and it conformed to the criteria of the Helsinki Declaration and ICH Guidelines for Good Clinical Practice. All the patients were fully informed 
about the aim of the study and agreed to the research methods. Written consent was obtained from the patients.

\section{RESULTS}

The study results revealed statistically significant differences in the activity of the temporal, masseter, and digastric muscles between two time points (before and on the first day of using new dentures) in the occlusion in the whole study group (I-II) $(p<0.05)$ (Table 1$)$. With respect to the sternocleidomastoid muscle, only on the left side was a statistically significant difference noted $(p>0.05)$ (Table 1$)$. In the whole group there was no statistically significant difference of pre- and post-treatment values of muscular activity of all the muscles in the opened mouth position (I-II stage comparison) $(p>0.05)$ (Table 1). After three months of adaptation statistical differences were observed only in the case of masseter muscles, right temporal, and left digastric (I-III stage comparison) $(p<0.05)$. With respect to the opened mouth position, statistically significant differences were observed in the muscular activity of the masseter and digastric on the right side and temporal, and the masseter and digastric on the left side (I-III stage comparison) $(p<0.05)$ (Table 1$)$. On the first day of using new complete dentures, in the whole group, a decreasing tendency of muscular activity was noted (Table 1). After three months of adaptation activity, the temporal, masseter, and digastric muscles on the right side as well as all muscles on the left side increased in comparison to the observed activity at II stage (Table 1).

In women statistically significant differences in occlusion were stated with respect to the activity of temporal, masseter, and digastric muscles on the right side and temporal, digastric, and sternocleidomastoid muscles on the left side at I-II stage comparison $(p<0.05)$ (Table 2). Three months after prosthetic treatment, statistical differences were observed only in the case of right temporal and digastric muscles in the occlusion $(p<0.05)$ (Table 2).

In men statistically significant differences were observed in the occlusion in the case of right masseter and digastric muscles and left masseter, digastric, and sternocleidomastoid muscles (I-II stage comparison) $(p<0.05)$ (Table 3). No statistically significant differences were noted at I-III stage comparison $(p>0.05)$.

With respect to gender no statistically significant differences were noted $(p>0.05)$ (Table 4$)$.

\section{DISCUSSION}

The reconstruction of the vertical occlusal dimension modified the functioning of the masticatory system. The introduction of the new dental restorations (complete dentures) resulted in a periodic reduction in the activity of the muscles responsible for the mobility of the mandible (Tables 1-3). As a result of the rapid adaptation, after three months an increase in activity was noted. In the case of masseter muscles, the obtained values were slightly lower than those noted in the presence of previously used prostheses. These observations coincide with those reported by other authors [27]. An important benefit of the prosthetic rehabilitation was the reduction of the activity of digastric muscles in the centric occlusion (Tables 1-3). Increased activity of these muscles is probably co-responsible for the resorption of the alveolar part of the mandible. The distribution of the activity observed in the study emphasises the symmetry and synergy of the pairs of individual muscles in the performance of specific movements. The preserved balance may indirectly indicate bilateral chewing. It should be noted that the observed adaptation in the neuromuscular system is not always synonymous with achieving optimal chewing capacity in this group of patients. According to some authors, this is possible only after one year of using newly made prosthetic restorations [15].

Amplitudes of stimulation obtained in the complete denture wearers were significantly different from those recorded in people with full dental arches [1, 41]. Alajbeg et al. [1] stated that in centric occlusion in edentulous people muscular activity decreases. With maximum opening of the mouth the activity profile of digastric muscles (venter anterior) is similar to that observed in adulthood (60.9 \pm 7.8 years) and significantly lower than that seen in young people $(26.7 \pm 2.8$ years $)$. In protrusion and lateral movements, muscle activity was highest in the toothless group [1]. Perhaps this is the effect of a bilateral balanced occlusion. The authors did not indicate what type of occlusion the examined persons presented or what kind of artificial teeth were used in the dentures. Hayakawa et al. [18] stated that the relining of the lower prosthesis with soft material contributes to the improvement of chewing capacity by increasing stabilisation, and reducing the amplitude and time of chewing, leading to a decline in the muscular function.

There is a direct relationship between muscular activity and the number of generated chewing forces [10]. The degree of compression of the alveolar processes of the upper jaw and the alveolar part of the mandible is closely related to the number of teeth present in the dental arches $[2,19,25]$. The periodontal proprioceptors and the pain threshold determines the magnitude of the masticatory system load. However, some authors attribute the supreme role to occlusal contacts and not to the number of teeth [4]. The previously mentioned concept of occlusion provided by canine guidance is gaining importance. It limits the friction surface of the teeth during eccentric movements of the mandible, reducing the area of application of force, thus significantly reducing the value of generated potentials [32]. Comparative assessment of edentulous people confirms the importance of canine guidance, indicating an upward tendency of recorded amplitudes of muscular activity in people with bilateral balanced occlusion [16]. 


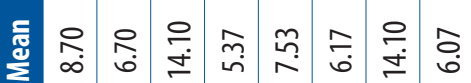

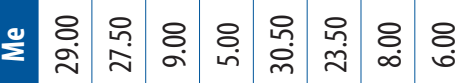

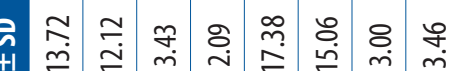

$\stackrel{\otimes}{ \pm}$

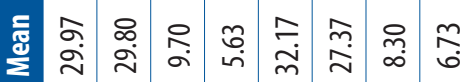

紊

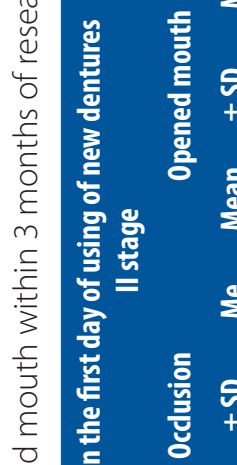

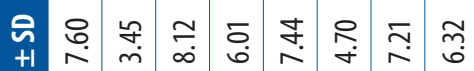
覀

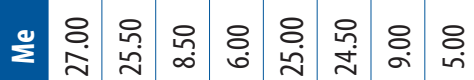

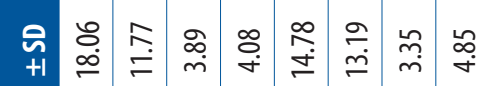

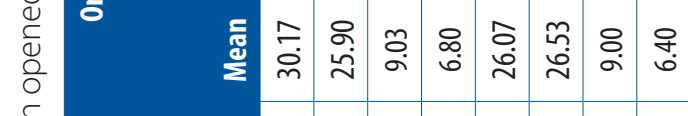
高 =

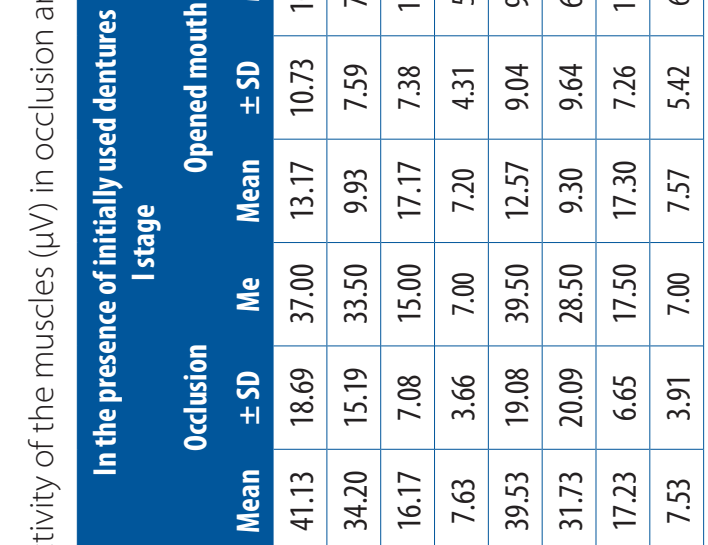

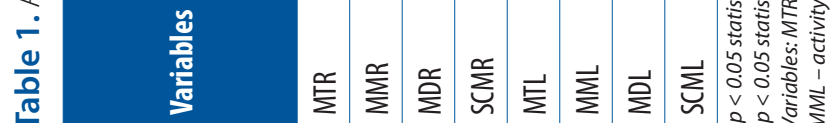



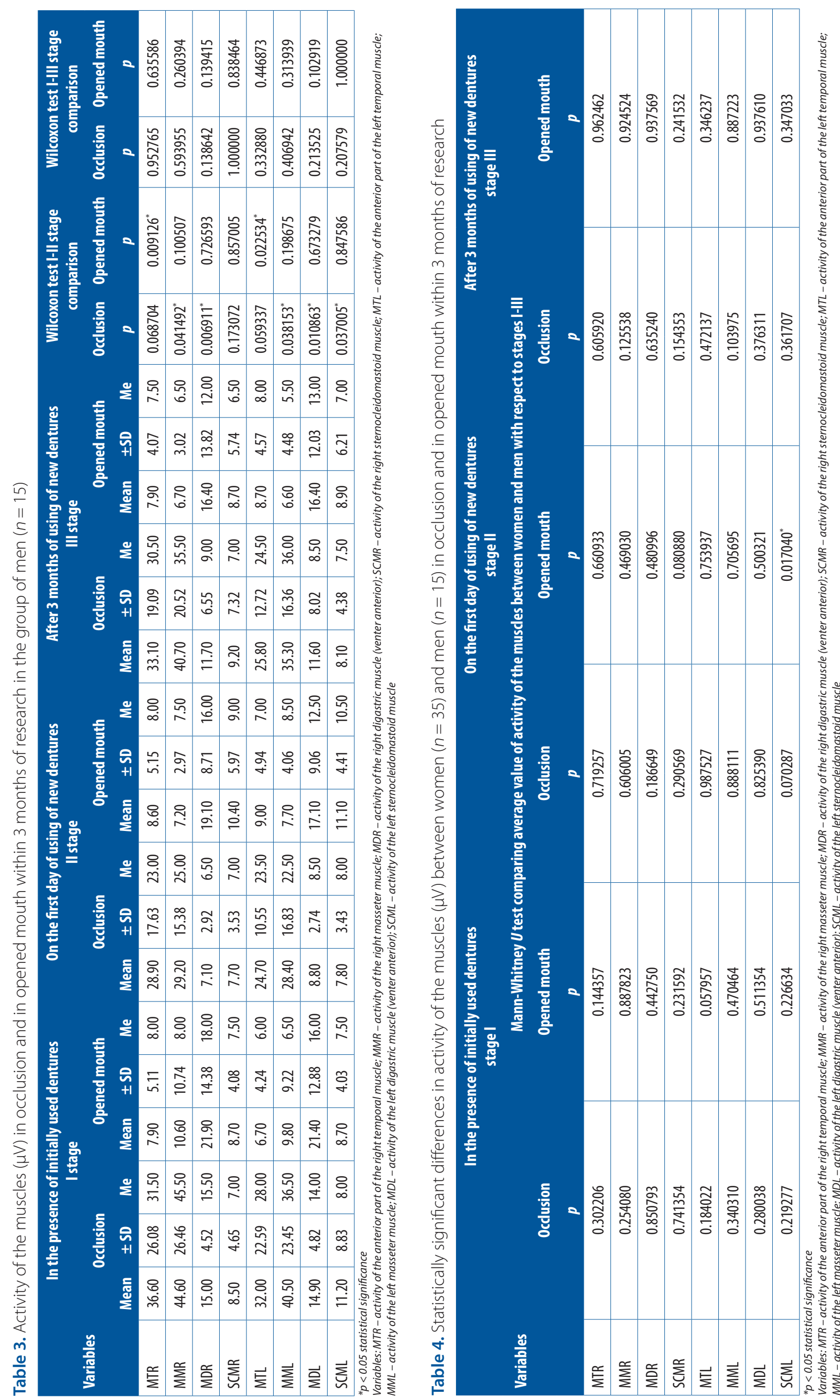
These observations are justified in anatomic relationships. The position of the selected teeth close to the axis of the temporomandibular joint results in an upward tendency of the occlusal force load [36]. In the area of molars, chewing forces are the greatest. Perhaps this is the effect of close proximity to the masseter muscle in this region and simultaneous mono-occlusion in the anterior teeth, as well as the result of reducing the distance between the given tooth and the axis of rotation of the mandible. In natural dentition, group function assumes an occlusal load proportional to the number of anatomical units remaining in occlusal contact with each other. In the case of tooth wear, horizontal attrition often determines the inclusion of more teeth in the mandible guidance profile. Taking over the occlusal load from many functional areas of the dental arch affects the overall increase in chewing forces remaining in directly proportional relationships to the level of generated bio-functional potentials of the muscles. Edentulous people equipped with complete dentures show some analogy. The idea of a bilaterally balanced occlusion assumes a symmetrical homogenous occlusal force distribution on both sides of the dental arch both in the case of latero- and mediotrusion. Presumably, however, the bilateral multi-point balanced occlusion in the eccentric position of the mandible contributes to the increase of EMG potentials.

The general balance of muscle activity in the group of complete denture wearers is lower than in the case of natural teeth. Although the efficiency of the masticatory system in the edentulous is limited, it seems that it is one of the main self-preservation mechanisms conditioning the prevention of atrophy of the jaws. In addition, the use of canine guidance in the total prostheses may be conducive to slowing down backward processes that may worsen, over the course of time, the possibility of further rehabilitation.

One of the reasons for the general reduction of muscle activity in the group of edentulous people is the loss of periodontal fibres. The periodontium contains receptors that determine the level of compression of the bone bases of the jaws [27]. The loss of the suspension apparatus that absorbs the chewing forces and the loss of the proprioceptors located in it limits the efficiency of the masticatory system in comparison to the possibilities observed in the presence of natural teeth $[26,31,33]$. The previously mentioned osseoperception takes over the role. In addition, unfavourable oral conditions, sharp edges of the alveolus after extractions, or pain in the projection of the mental foramen - in the form of physiological reflex - can shape individual pain thresholds, thus determining an individual self-preservation mechanism. In addition, the psychological factors, fear of damaging the prosthetic base and complete dentures due to the lack of stabilisation of the lower prosthesis, limits the level of generated occlusal forces [1]. Edentulous people are able to release more muscle activity than is actually necessary. In complete denture wearers, partial improvement of the efficiency of the masticatory system can be achieved by performing overdenture prostheses supported by implants. According to numerous authors, this is how $3 / 4$ of the chewing capacity of natural teeth is restored $[2,11,39]$.

In edentulous patients, a decrease in the activity of individual muscle groups can be the result of remodelling muscle tissue at the macroscopic level. The width of the superficial layer of the masseter muscle is $2.7 \mathrm{~mm}$ narrower than in the people with natural dentition. Kasai et al. [20] noted that also the dimension between the front edge of the masseter muscle and the point within link between corpus of the mandible and its ramus is statistically $4 \mathrm{~mm}$ shorter. One of the causes of the observed atrophy may be the above-mentioned decreased efficiency of the masticatory system due to the lack of sufficient stimulus for the primary functioning of the masseter muscle. The overall decline in chewing efficiency affects the reduction of muscle fibres.

A negative effect on the nervous and musculoskeletal system is surely the diet of the edentulous people, who prefer soft consistency food. Probably the introduction of some strength triggers would restore the previous activity [37]. An example is research carried out in young people with full dental arches and features of a long face. Application of exercises leads to increased activity of the chewing muscles as well as to the mandibular antero-rotation [40]. Yanıkoğlu et al. [42] noted changes in mandibular angulation in the edentulous after supplying complete dentures. In the case of edentulous people, the use of overdentures supported on implants could probably reduce atrophy of masseter muscles. The use of such solutions definitely improves the quality in the functioning of the masticatory system. While the improvement in efficiency is obvious, there are no reports that clearly confirm the inversion of involutional processes in the superficial layer of the masseter muscle in this group of patients.

Activity of the chewing muscles can be determined by a specific skeletal pattern $[13,38]$. Numerous studies indicate a close relationship between long or short face syndrome and correspondingly lower or higher average values of the muscular activity with respect to the normognathic face. The morphological profile of the face is phylogenetically conditioned. The tendency for posterorotation of the mandible is the result of civilisation progress. This is confirmed by retrospective studies. Skulls of people living in the Middle Ages showed a mediocre inclination of the mandibular body to the base of the jaws and a tendency towards antero-rotation. In addition, tooth wear and a slight percentage of malocclusion were observed. Probably it was related to the diet occurring at that time, requiring a significant amount of muscle use in the process of chewing food, indirectly constituting a trigger factor for the masticatory system. Analogous morphological features are currently observed in the group of people affected by the pathological tooth wear and the practice of bodybuilding [21]. 
The presence of tooth wear in the case of mandibular antero-rotation suggests that in complete dentures acrylic teeth are more quickly rubbed off at the toothless stage. Van Spronsen emphasises that the development and functioning of the muscular system are the effect of skeletal determination rather than the cause of its development [40]. In people with features of a long face, the dimensions of the muscles responsible for mandibular elevation are up to $33 \%$ lower than in the control group [40]. In the assessment of the EMG daily balance, some authors report no statistically significant differences in the activity of the muscle results obtained in the comparison of skeletal types [9]. In the case of toothless people, there are no objective methods that allow unambiguous classification of individual clinical cases to one of the mentioned syndromes. There are no reports on this subject in the literature. Clinical experience of the dentists and individual facial assessment skills may prove helpful. Nevertheless, this is an approximate value.

In addition to morphological determination, the participation of certain types of muscle fibres in the number of triggered chewing forces is emphasised. Regarding the myosin isoforms in the masticatory system, eight types of fibres were distinguished, while for other skeletal muscles only three $[23,30]$. The types of muscle fibres are associated with a specific skeletal profile. Type I (slowtwitch red fibres) dominates in the case of mandibular postero-rotation and skeletal open bite. On the other hand, in the situation of deep bite, type II (fast-twitch white fibres) predominates, allowing immediate reaction [40]. Some authors indicate the presence of a type of relationship between types of muscle fibres and vertical occlusal dimension. It is difficult to say what reference these observations have to edentulous people. There is no information on this subject in the literature. There are some reports indicating the possibility of converting some specific types of fibres into another [28, 29]. Molecular modification of type II in I may explain the decrease in the activity of the masseter muscles in a situation of toothlessness indirectly caused by the loss of natural teeth. Perhaps patients treated with overdentures anchored on implants would have the opposite effect. Presumably in this case, type II fibres should dominate.

Muscle activity can be the result of gnatal defects imposing a specific stimulation profile. In the case of retrognathic patients, some authors reported a statistically significant reduction in the activity of the masseter and temporal muscles in the maximum intercuspation [12, 17]. Others stated no difference in the activity of the muscles in the centric occlusion with respect to three possible skeletal classes of disorders [24]. In the case of edentulous people, morphological deviations may be one of the factors directing a specific tendency of changes. It is often difficult to assess whether a person with total deficiencies was affected by one of the gnathic disorders.

Sometimes this is enforced by clinical procedures, especially in the phase of determining the central occlu- sion and more precisely the central position of the mandible. Often the initial assessment of the facial profile suggests deviations from normognathic relations.

The influence of skeletal relationships on the functioning of the neuromuscular system may also highlight the disorders associated with asymmetry [8]. In the case of hemifacial microsomia, abnormalities of the mandible (laterogenia), and cervical torticollis, the dysfunctional side could show a reduced EMG biopotential profile.

Other factors that could increase muscle activity include stress associated with an individual psychological patient's profile or caused by the circumstances of the conducted research (noise, unsteady test conditions, the presence of third persons). Moreover, in the situation of difficult conditions of the prosthetic base, the proper state of neuromuscular control may be a factor determining the retention of prostheses, with another one affecting the level of generated muscle potentials. In the presented study group, patients were not selected due to the condition of the prosthetic base including atrophy of the jaws. Reports from other authors showed no statistically significant correlation between patients afflicted with the osteoporosis process and the level of generated EMG potentials [34].

Small deviations of the amplitude with no statistically significant differences observed between both sexes may be the result of morphological dimorphism (Tables 2-4). Ghosh et al. [14] point to the top-down determination of greater muscle strength in men than in women. The tendency for the mandibular postero-rotation of the mandible is attributed to the female. Antero-rotation is more often observed in men. The skeletal growth profile of both jaws is associated with a different size of the masseter muscles, which is the result of differences in the structure of the mandibular ramus. In the case of men in the sagittal plane, the base of the condylar head of the mandible is bent in the dorsal direction. In the frontal view, the deflection of the central part of the ramus towards the midline is recorded. The presence of the concave surface is a wide locus for the masseter muscle. In retrospective studies these features constitute attempts to determine gender based on the anatomy of the mandible. At once, they explain the relationship of the long and short face syndrome with a specific profile of muscle activity. The greater volume of masseter muscles can be one of the factors favouring the progression of activity obtained during EMG registration.

\section{CONCLUSIONS}

Fabrication of new complete dentures, associated with reconstruction of vertical occlusal dimension, changes of central position of the mandible, and modification of the occlusion of the artificial teeth, leads to a temporary reduction of activity in the chewing muscles, then a period of adaptation, and finally incorpo- 
ration into growth. Both before and after three months of adaptation, muscular activity does not differ statistically with respect to gender.

\section{ACKNOWLEDGEMENTS}

This material was based on statutory work supported by the Medical University (No. 4-08676L).

\section{CONFLICT OF INTEREST}

The authors declare no potential conflicts of interest with respect to the research, authorship, and/or publication of this article.

\section{References}

1. Alajbeg IZ, Valentic-Peruzovic M, Alajbeg I, Cifrek M. The influence of age and dental status on elevator and depressor muscle activity. J Oral Rehabil 2006; 33: 94-101.

2. Bakke M, Holm B, Gotfredsen K. Masticatory function and patient satisfaction with implant-supported mandibular overdentures: a prospective 5-year study. Int J Prosthodont 2002; 15: 575-581.

3. Bakke M, Holm B, Jensen BL, Michler L, Møller E. Unilateral, isometric bite force in 8-68-year-old women and men related to occlusal factors. Eur J Oral Sci 1990; 98: 149-158.

4. Bakke M. Bite Force and occlusion. Semin Orthod 2006; 12: 120126.

5. Braun S, Hnat WP, Freudenthalter JW, Marcotte MR, Hönigle K, Johnson BE. A study of maximum bite force during growth and development. Angle Orthod 1996; 66: 261-264.

6. Cecilio FA, Regalo SCH, Palinkas M, et al. Aging and surface EMG activity patterns of masticatory muscles. J Oral Rehabil 2010; 37: 248-255

7. Dahl BL, Carlsson GE, Ekfeldt A. Occlussal wear of teeth and restorative materials. A review of classification, etiology, mechanisms and some aspects of restorative procedures. Acta Odontol Scand 1993; 51: 299-311.

8. Dong Y, Wang XM, Wang MQ, Widmalm SE. Assymetric muscle function in patients with developmental mandibular asymmetry. J Oral Rehabil 2008; 35: 27-36.

9. Farella M, Michelotti A, Carbone G, Gallo LM, Palla S, Martina R. Habitual daily masseter activity of subjects with different vertical craniofacial morphology. Eur J Oral Sci 2005; 113: 380-385.

10. Ferrario VF, Sforza C, Zanotti G, Tartanglia GM. Maximal bite force in healthy young adults as predicted by surface electromyography. J Dent 2004; 32: 451-457.

11. Fontijn-Tekamp FA, Slagter AP, Van der Bilt A, et al. Biting and chewing in overdentures, full dentures and natural dentitions. J Dent Res 2000; 79: 1519-1524.

12. Gadotti IC, Berzin F, Biasotto-Gonzalez D. Preliminary rapport on head posture and muscle activity in subjects with class I and II. J Oral Rehabil 2005; 32: 794-799.

13. Garcia-Morales P, Buschang PH, Throckmorton GS, English JD. Maximum bite force, muscle efficiency and mechanical advantage in children with vertical growth patterns. Eur J Orthod 2003; 25: 265-272.

14. Ghosh S, Vengal M, Pai KM. Remodeling of the human mandible in the gonial angle region: a panoramic, radiographic, cross-sectional study. Oral Radiol 2009; 25: 2-5.

15. Goiato MC, Garcia AR, Dos Santos DM, Zuim PR. Analysis of masticatory cycle efficiency in complete denture wearers. J Prosthodont 2010; 19: 10-13.
16. Grubwieser G, Flatz A, Grunert I, Kofler M, Ulmer H, Gausch K. Quantitative analysis of masseter and temporalis EMGs: a comparison of anterior guided versus balanced occlusal concepts in patients wearing complete dentures. J Oral Rehabil 1999; 26: 731-736.

17. Harper RP, De Bruin H, Burcea I. Muscle activity during mandibular movements in normal and mandibular retrognathic subjects. J Oral Maxillofac Surg 1997; 55: 225-233.

18. Hayakawa I, Hirano S, Takahashi Y, Keh ES. Changes in the masticatory function of complete denture wearers after relining the mandibular with a soft denture liner. Int J Prosthodont 2000; 13: 227-231.

19. Helkimo E, Carlsson GE, Helkimo M. Bite force and state of dentition. Acta Odontol Scand 1977; 35: 297-303.

20. Kasai K, Richards LC, Kanazawa E, Ozaki T, Iwazawa T. Relationship between attachment of the superficial masseter muscle and craniofacial morphology in dentate and edentulous humans. J Dent Res 1994; 73: 1142-1149.

21. Kiliardiasis $S$. The importance of masticatory muscle function in dentofacial growth. Semin Orthod 2006; 12: 110-119.

22. Lestrel PE, Kapur KK, Chauncey HH. A cephalometric study of mandibular cortical bone thickness in dentulous persons and denture wearers. J Prosthet Dent 1980; 43: 89-94.

23. McComas AJ. Oro-facial muscles: internal structure, function and ageing. Gerodontology 1998; 15: 3-14.

24. Miralles R, Hevia R, Contreras L, Carvajal R, Bull R, Manns A. Patterns of electromyographic activity in subjects with different skeletal facial types. Angle Orthod 1991; 61: 277-283.

25. Miyaura K, Matsuka Y, Morita M, Yamashita A, Watanabe T. Comparison of biting forces in different age and sex groups: a study of biting efficiency with mobile and non-mobile teeth. J Oral Rehabil 1999; 26: 223-227.

26. Miyaura K, Morita M, Matsuka Y, Yamashita A, Watanabe T. Rehabilitation of biting abilities in patients with different types of dental prostheses. J Oral Rehabil 2000; 27: 1073-1076.

27. Piancino MG, Farina D, Talpone F, et al. Surface EMG of jawelevator muscles and chewing pattern in complete denture wearers. J Oral Rehabil 2005; 32: 863-870.

28. Rowlerson A, Raoul G, Yousif D, et al. Fiber-type differences in masseter muscle associated with different facial morphologies. Am J Orthod Dentofac Orthop 2005; 127: 37-46.

29. Schiaffino S, Reggiani C. Myosin isoforms in mammalian skeletal muscle. J Appl Physiol 1994; 77: 493-501.

30. Sciote JJ, Rowlerson AM, Hopper C, Hunt NP. Fibre type classification and myosin isoforms in the human masseter muscle. J Neurol Sci 1994; 126: 15-24.

31. Shinkai RS, Hatch JP, Sakai S, Mobley CC, Saunders MJ, Rugh JD. Oral function and diet quality in a community-based sample. J Dent Res 2001; 80: 1625-1630.

32. Shinogaya T, Kimura M, Matsumoto M. Effects of occlusal contact on the level of mandibular elevator muscle activity during maximal clenching in lateral positions. J Med Dent Sci 1997; 44: 105-112.

33. Shinogaya T, Toda S. Rehabilitation of occlusal support by removable partial dentures with free-end saddles. Eur J Prosthodont Restor Dent 2003; 11: 107-113.

34. Siéssere S, de Albuquerque Lima N, Semprini M, et al. Masticatory process in individuals with maxillary and mandibular osteoporosis: electromyographic analysis. Osteoporos Int 2009; 20: 1847-1851.

35. Sonnesen L, Bakke M. Bite force in pre-orthodontic children with unilateral crossbite. Eur J Orthod 2001; 23: 741-749.

36. Spencer AM. Force production in the primate masticatory system: electromyographic tests of biomechanical hypotheses. J Hum Evol 1998; 34: 25-54.

37. Stephan $\mathrm{CN}$. The human masseter muscle and its biological correlates: a review of published data pertinent to face prediction. Forensic Sci Int 2010; 201: 153-159. 
38. Ueda HM, Miyamoto K, Saifuddin M, Ishizuka Y, Tanne K. Masticatory muscle activity in children and adults with different facial types. Am J Orthod Dentofac Orthop 2000; 118: 63-68.

39. van Kampen FM, van der Bilt A, Cune MS, Bosman F. The influence of various attachment types in mandibular implant-retained overdentures on maximum bite force and EMG. J Dent Res 2002; 81: 170-173.

40. van Spronsen PH. Long-face craniofacial morphology: cause or effect of weak masticatory musculature? Semin Orthod 2010; 16: 99-117.

41. Veyrune JL, Mioche L. Complete denture wearers: elektromyography of mastication and texture perception whilst eating meat. Eur J Oral Sci 2000; 108: 83-92.

42. Yanıkoğlu ND, Yılmaz B. Radiological evaluation of changes in the gonial angle after teeth extraction and wearing of dentures: a 3-year longiitudinal study. Oral Surg Oral Med Oral Pathol Oral Radiol Endod 2008; 105: e55-e60. 